\title{
CRUZ E LEGIÃO ROMANA: O IMAGINÁRIO POPULAR NA PALESTINA DO $1^{\circ}$ SÉCULO
}

Luiz Alexandre Solano Rossi ${ }^{1}$

\begin{abstract}
Resumo
A partir do ano 63 a.C. a nova ordem imperial chega na Palestina. Um império desejado pelos deuses e considerado eterno como os próprios deuses o são. No entanto a eternidade do Império passa por instrumentos de violência contra os povos subjugados no presente. Assim, a cruz e a legião romana se tornarão símbolos no imaginário coletivo dos camponeses na Palestina. Imaginário que se constrói a partir de imagens presente no próprio cotidiano. Cruzes e soldados estavam presentes no cenário da Palestina para relembrar a qualquer camponês de sua vulnerabilidade e, ao mesmo tempo, reafirmar a perenidade de um Império divinizado pela força.
\end{abstract}

\section{Palavras-chave}

Cruz; violência; império; nova ordem mundial; legião.

\begin{abstract}
From the year 63 BCE the new imperial order arrives in Palestine. An empire desired by the gods and considered eternal as the gods themselves are. Nevertheless, the eternity of the Empire passes through instruments of violence against the peoples subjugated in the present. Thus, the cross and the Roman legion will become symbols in the social imaginary of the Palestine's peasants. Imaginary that is constructed from images present in the daily routine. Crosses and soldiers were present in the Palestinian scenario to remind any peasants of their vulnerability and at the same time to reaffirm the perennity of an empire deified by force.
\end{abstract}

Keywords

Cross; violence; Empire; New World Order; legion.

\footnotetext{
1 Professor Doutor, Pontifícia Universidade Católica do Paraná/Uninter, Curitiba, Brasil. E-mail: luizalexandrerossi@yahoo.com.br
} 


\section{Ao professor Funari}

Corria o ano de 2003, época em que preparava um projeto para dar início à pesquisa de pós-doutorado. Projeto finalizado, faltava-me um pesquisador para supervisionar minha pesquisa. Foi justamente nessa época que um amigo pesquisador me repassou, gentilmente, o endereço eletrônico do Prof. Pedro Paulo Funari. Até aquele momento não o conhecia pessoalmente. Afinal, éramos de áreas do conhecimento distintas, ou seja, ele de História e eu de Bíblia.

Enviei o primeiro e-mail me apresentando e expressando meus objetivos com a possível pesquisa que propunha, mas uma série de dúvidas e receios acompanhava cada palavra. Pensava que um pesquisador do porte dele, consagrado nacional e internacionalmente e referência em sua área, jamais se daria o trabalho de responder mais uma mensagem que chegava em sua caixa postal. Qual não foi a minha surpresa quando, no dia seguinte, a resposta do prof. Funari já se encontrava em minha caixa postal. Resposta que li com um grande sorriso! Para minha alegria, ele aceitava ser meu supervisor e propunha uma reunião de trabalho para os próximos dias em São Paulo.

Desde aquele momento o prof. Funari veio a se tornar meu supervisor de pesquisa no pós-doutorado na UNICAMP pelos próximos dois anos. Um tempo extremamente bem aproveitado tanto para a vivência da amizade quanto pela produção acadêmica que se seguiu. No entanto, mais do que supervisor, o prof. Funari se tornou um amigo. Assim, se o pósdoutorado finalizou, a amizade, a influência e a dedicação à pesquisa que aprendi caminhando nos passos do prof. Funari permanecem até hoje. A multiplicação de agradecimentos jamais seria suficiente de minha parte. Por isso, respondo à amizade do Prof. Funari com porção redobrada de amizade e de carinho, ad aeternum.

\section{Introdução}

O avanço do Império Romano em direção da Palestina pode ser datado em 63 a.C., quando Pompeu conseguiu tomar Jerusalém sem muitos problemas. Uma conquista que fará com que a Palestina permaneça subjugada à águia romana e cujo domínio alimentaria o ódio do povo por muitos séculos. A nova ordem imperial romana ensaiava seus primeiros passos trazendo, como instrumentos para estabelecer a nova ordem imperial, as legiões e a cruz. 
Cruz e legião muito possivelmente povoavam o imaginário dos camponeses na Palestina. Apresentavam-se como representações simbólicas a partir de um cotidiano marcado tanto pela violência física quanto pela violência econômica. Pelas estradas, vilas e cidades onde os olhos dos camponeses podiam contemplar as múltiplas e infindáveis cruzes cravando a terra de violência e/ou quando os ouvidos podiam ouvir o som das botas dos soldados legionários marchando em ritmo de conquista, os camponeses saberiam que o imaginário havia se tornado real.

Ao falar do "imaginário" do povo da Palestina recorro ao conceito de imaginário estabelecido por Hilário Franco Júnior (1998: 23) como "um conjunto de imagens visuais e verbais gerado por uma sociedade (ou parcela desta) na sua relação consigo mesma, com outros grupos humanos e com o universo em geral". Dessa forma, é possível concluir que todo imaginário - deve-se salientar a necessidade de se perceber os muitos imaginários possíveis e não cair no erro de reduzir a "um só imaginário" - é eminentemente coletivo e, portanto, não poderia ser confundido com atividade psíquica individual ou ainda à somatória de imaginações.

A Palestina podia ser descrita como um conjunto de cidades dominadas e submetida ao poder romano. É possível afirmar que a maior parte da história judaica na Palestina (e as províncias da Galiléia, Samaria e Judéia) do primeiro século envolveu protesto e resistência contra as provocações e opressão romana (Horsley, 1987: 33). As principais vítimas da política expansionista romana eram justamente os camponeses. Para eles, a dominação romana significava fundamentalmente uma pesada tributação e, mais do que isso, uma séria ameaça a sua existência, haja vista que muitos deles foram expulsos de suas terras (Horsley; Hanson, 1995: 43).

Não é possível minimizar o período da dominação romana. Nela encontramos o cenário apropriado para a emergência de lutas, guerrilhas e sublevações populares contínuas. A Palestina poderia ser descrita como um dos maiores focos de rebeldia contra a expansão imperial romana. Poderíamos ainda acrescentar que na Palestina do primeiro século a situação econômica da população encontrava-se em queda vertiginosa, refletindo na deterioração da qualidade de vida. As pessoas mais vulneráveis viviam cercadas pela instabilidade e pela penúria. Horsley (1987: 29) descreve que a violência na região era "institucionalizada" porque havia sido determinada pela conquista imperial. Ele afirma que os romanos possuíam sua ideologia autolegitimadora de "defender seus amigos e aliados" e de levar "civilização" e "paz" para o resto do mundo. 
Todavia, a conquista imperial era marcada pelo uso abusivo da violência, atingindo populações inteiras seja pelo assassinato ou pela escravidão.

Rocha (2004: 245) apresenta um cenário real do primeiro século sob o domínio do Império Romano:

Em meados do século I, calcula-se entre 50 e 80 milhões os habitantes do Império Romano, dos quais cerca de $90 \%$ viviam no campo. Porém a terra, a principal fonte de sobrevivência para a população do Império, inclusive aquela da Palestina, era muito mal distribuída. Na península Itálica e nas Províncias a maioria das terras produtivas estava nas mãos de uma minoria. No Egito encontramos o caso de 42 agricultores partilhando de uma mesma casa. Sêneca indica que os pobres constituíam a maior parte da população e que a situação tinha poucas chances de ser mudada.

Sobre isso Moxnes escreveu (p. 36-37): “Toda descrição da economia antiga deve partir do fato de que ela estava baseada na agricultura. A agricultura não era apenas mais um setor da economia; constituía a própria base dessa economia". Claro está que, a partir da nova ordem imperial, a cultura de subsistência passará por um período de franco declínio inaugurando, com isso, instabilidade social, econômica e, também, política. As operações militares periódicas em diversos pontos da Galiléia e a carga econômica extra imposta sobre os camponeses pelo tributo romano e pela arrecadação de taxas especiais tiveram um efeito desastroso sobre os camponeses galileus. Os impostos exigiam do povo um grande esforço que levava, irremediavelmente, à miséria. A prática da cobrança de impostos beneficiava um determinado grupo social de Roma que vivia a custa dos impostos. A cobrança de impostos, somado a outras formas de opressão, produzia o aumento do número de pobres, marginalizados, enfermos entre outros, que se tornavam reféns das estruturas de poder romano. Através destas políticas, a Galiléia viu crescer o número de enfermos, de desempregados e de agricultores semterra.

Crossan (2004: 201-202) faz uma importante diferenciação entre império agrário mercantil que caracteriza a nova ordem imperial e impérios agrários tradicionais, modelo que predominava na Palestina antes da chegada do Império Romano:

No império agrário tradicional, a aristocracia toma o produto excedente da classe camponesa; no império agrário mercantil, a aristocracia toma a terra da classe camponesa. O primeiro devora o esforço e o produto dos camponeses, o segundo a própria identidade e dignidade deles. No império agrário tradicional, a terra é herança familiar a ser conservada pela classe camponesa. No império agrário mercantil, a terra é mercadoria empresarial a ser explorada pela aristocracia. 
Parece óbvio concluir que a partir de todos os dados acima citados, que a maior parte dos que se opunham a Roma pertencia sempre à classe rural, indicando, dessa forma, os motivos que levaram às revoltas camponesas na Palestina entre os anos 66 e 70. Mas também é possível destacar a opressão extremamente severa sobre a população judaica da Palestina por parte de romanos e da própria aristocracia local, que incluía os sumos sacerdotes. Rocha (2004: 246) afirma que em fins da era de Augusto (aprox. 14), a verdadeira camada dominante era constituída aproximadamente por 160 pessoas. Um exército permanente de 350.000 a 400.000 homens garantia o status quo, tornando ineficaz qualquer revolta contra o domínio dos romanos e das lideranças locais, suas aliadas.

\section{A força sobre-humana das legiões}

Ao longo da literatura encontramos muitas referências não somente a respeito da capacidade militar de Roma bem como sobre sua formação. Nesse sentido Koester (2005, p. 6) afirma que Vespasiano, durante o inverno de 66, reuniu três legiões e várias tropas auxiliares; em outro momento traz informações, ainda que genéricas, a respeito da capacidade logística e da técnica militar ao afirmar que numa das incursões de Vespasiano o cerco durou "várias semanas". Josefo (Guerras, Livro II), por sua vez, insiste em descrever o poder do exército romano ao registrar em várias ocasiões: "Varo deixou na cidade uma das três legiões" e ainda "os romanos se impuseram com sua experiência guerreira (Guerras 2.47); "Petrônio se dirigiu desde a Antioquia para a Judéia com três legiões e com muitos aliados da Síria" (Guerras, 2.186); "Floro se dirigiu a Jerusalém com um exército de cavalaria e infantaria com a finalidade de intervir ali com armas romanas e espoliar a cidade com terror e ameaças" (Guerras 2.295) e a respeito da campanha de Céstio nos informa que “transferiu de Antioquia a duodécima legião completa, dois mil soldados selecionados das outras legiões, suas tropas de infantaria e quatro alas de cavalaria (2.498).

Porém, uma das maiores questões relativas ao exército romano permanece sem resposta: nenhuma fonte existente afirma o número preciso de homens nas legiões. Desse modo, poderíamos nos aproximar de Crossan (1995: 147) que afirma que uma legião consistia de 6.000 homens ou ainda de Southern (2007: 99) que indica que é possível que o número de legionários fosse diferente nas províncias e em épocas diferentes e que, por isso, a maioria dos pesquisadores acabe optando por 
uma força legionária entre 5.000 e 6.000 homens. Além das legiões havia as tropas auxiliares, recrutadas nas províncias e uma frota. Cada legião compreendia 10 coortes e 6 centúrias constituíam uma coorte. Originalmente todos os legionários eram recrutados dentre os cidadãos romanos, mas a partir do momento em que a fonte de recursos humanos entrasse em processo de redução, a distinção entre cidadãos e não cidadãos era completamente ignorada.

A respeito da cadeia de comando, Koester (2005: 237) nos informa que uma legião era comandada por um legado da classe senatorial. A ele estavam subordinados seis tribunos militares, o primeiro dos quais provinha do senado, e os demais da classe dos equestres, de onde saíam também os comandantes das tropas auxiliares. Esses oficiais serviam apenas por períodos limitados, mas os equestres podiam servir por um período de tempo mais prolongado. Os oficiais permanentes do exército eram os centuriões, cidadãos comuns para quem o serviço militar era uma profissão para toda a vida. Uma subdivisão especial do exército era a guarda imperial, o pretoriano, que se transformara num corpo de elite e também servia como uma espécie de academia militar. Os pretorianos, uma corporação com aproximadamente 4.500 homens e comandada por dois prefeitos, eram a única unidade do exército estacionada em solo italiano.

Do ponto de vista da estratégia político-militar era de suma importância que a maioria das legiões estivesse estacionada nas províncias fronteiriças. Afinal, a administração dessas províncias pelo imperador estava estreitamente relacionada com seu imperium militar. A força política do imperador era garantida pela presença e força das legiões, que às vezes podiam nomear o imperador.

A força legionária romana era considerada letal. Dois exemplos são significativos: 1) O governador denominado Varo mobilizou três legiões e tropas auxiliares para esmagar revoltas na terra judaica. Quando ele chegou a Jerusalém, crucificou, segundo o relato de Josefo (Guerra 2.75), "dois mil rebeldes". As crucificações em massa marcaram o começo e o fim da primeira guerra romano-judaica. 2) No início do verão de 66 d.C., Floro, governador romano da terra judaica, ordenou a suas tropas que atacassem dentro da cidade. O relato de Josefo (Guerra 2.306-308) fala por si mesmo:

Muito dos cidadãos pacíficos foram detidos e levados diante de Floro, que primeiro mandou que fossem açoitados e depois crucificados. O número total de vítimas nesse dia, incluindo mulheres e crianças, pois estas não mereciam perdão, chegava a três mil e seiscentos. A calamidade era agravada pelo aspecto 
sem precedentes da crueldade dos romanos. Pois Floro se aventurou nesse dia a fazer o que ninguém havia sequer tentado antes, isto é, açoitar diante de seu tribunal e pregar na cruz homens de nível de cavaleiros, homens que, se judeus por nascimento, foram pelo menos investidos com essa dignidade romana.

O exército romano em marcha deveria impressionar e alimentar o desespero das populações que se encontravam em seu caminho. Mas é preciso salientar que havia certa ordem na marcha militar. De acordo com Josefo (2009b, Guerra 3.115-126), no ano 67, o general Vespasiano, que ainda não era imperador, marchou em direção à Galiléia e colocou seu exército à vista do inimigo para infundir-lhes medo, com a seguinte ordem:

a) As forças auxiliares e arqueiros ligeiramente armados para checar o terreno e descobrir emboscadas;

b) Destacamento de infantaria e cavalaria com armamento pesado;

c) Dez homens de cada uma das centúrias com seu próprio equipamento e com instrumentos necessários para medir o traçado do acampamento;

d) Posteriormente seguiam os engenheiros para verificar as estradas, aplainar os caminhos difíceis e cortar árvores que impedissem o acesso;

e) O transporte das bagagens de Vespasiano e de seus oficiais protegidas pela cavalaria;

f) Atrás cavalgava o próprio Vespasiano com um destacamento da infantaria e da cavalaria assim como sua própria guarda pessoal;

g) Depois a cavalaria própria de cada legião;

h) Em seguida as mulas carregando as máquinas de sítio;

i) Adiante seguiam os oficiais: os comandantes das legiões, os prefeitos e tribunos com guardas;

j) Depois iam os estandartes com o símbolo da águia;

k) Seguiam aos estandartes as trombetas;

1) Após as trombetas seguiam as falanges com seus efetivos distribuídos em filas de seis com um centurião com o objetivo de supervisioná-la;

m) Seguiam os servos e as bagagens;

n) No final das legiões ia uma grande quantidade de mercenários que tinham a retaguarda protegida por soldados com armamentos pesados e ainda por um grande número de cavalarianos. 
O exército estacionado diante dos inimigos se apresentava como a própria imagem do terror e da violência que estava por chegar. No entanto, os soldados sedentos para entrar em combate, seguiam táticas de batalha bem definidas a fim de quebrar a linha de batalha inimiga, que podem assim ser descritas de acordo com Webster (1985: 232):

1) Nas batalhas no solo uma força é direcionada para o centro, com duas forças laterais e uma força reserva na retaguarda. As forças laterais e reservas devem ser fortes o suficiente para prevenir qualquer ataque ou manobra fora do flanco;

2) Uma linha de batalha oblíqua com a força lateral esquerda permanece em uma posição defensiva, enquanto a força lateral direita avança para tentar dominar o flanco esquerdo do oponente. Uma oposição a este movimento é fortalecer que a força esquerda com a cavalaria e as reservas, mas se ambos os lados obtiverem sucesso no front de batalha a tendência é que eles se movam num sentido anti-horário, cujo efeito variaria por causa da natureza do terreno;

3) Repete-se o posicionamento anterior, com exceção de que a força esquerda se torna agora mais forte e faz uma tentativa de um novo movimento que acontece a partir do momento que se sabe que a força direita do inimigo está enfraquecida;

4) As duas forças laterais avançam juntas, deixando o centro para trás. Esse movimento pode tomar o inimigo de surpresa e, consequentemente, deixar seu centro exposto e desmoralizado;

5) A mesma tática do anterior, mas o centro é escondido por arqueiros e infantaria leve que podem manter o centro inimigo distraído enquanto as forças laterais batalham;

6) Uma variação da tática 2 onde o centro e a lateral esquerda são mantidos atrás enquanto a força lateral direita tenta um movimento de retorno. Se a ação obtiver sucesso, a lateral esquerda, reforçada pelos reservas, pode avançar e esperar completar o movimento de ataque que comprimiria o centro;

7) É o uso do terreno apropriado em qualquer um dos flancos para protegê-los como sugerido na tática 2 .

A violência das legiões foge à compreensão. O mesmo Josefo relata que as tropas de Tito capturaram judeus mais pobres que fugiam de Jerusalém para buscar comida fora das muralhas e os torturaram, espancaram e crucificaram diante dos olhos dos defensores da cidade. Num caso, arrancaram as mãos de vítimas de tortura e as fizeram voltar, mutiladas, para a cidade, como meio de coagir os habitantes à rendição (Guerra, 5.11,5). Palavras carregadas de dor e de violência como chicotear, torturar, queimar os olhos e mutilar fazem parte do vocabulário de Josefo ao descrever a ação militar romana (5.49.9). 
Ao se pesquisar sobre a legião romana, não é possível passar desapercebido o texto de Marcos 5,1-17 que retrata, simbolicamente, a força sobre-humana de uma legião a partir de um episódio muito particular da ação de Jesus ao libertar o possesso de Gadara. Um relato que suscita várias perguntas e algumas delas se fazem especiais: a) o episódio revela alguma relação entre a opressão que o império romano exercia sobre a Palestina e o fenômeno de tantas pessoas possuídas pelo demônio à época de Jesus? b) seria uma forma doentia de se rebelar contra a submissão romana e o domínio dos poderosos? Mesmo que não entendamos a cura do endemoninhado geraseno como estritamente histórica, talvez seja possível afirmar que o imaginário do povo da Palestina estivesse povoado pelas imagens da opressão de Roma. Sim, provavelmente estamos diante da cura de um indivíduo, mas também não podemos e não devemos ignorar o simbolismo que a narrativa traz em seu interior. Muito possivelmente o caráter simbólico do texto incorpora e gera mais sentido.

Consequentemente, é possível afirmar que diante dos episódios de exorcismos de Jesus e, principalmente ao do geraseno, as pessoas simples da Galiléia entrevissem, a partir de seu imaginário coletivo, a rápida derrota dos romanos ou, nas palavras de Crossan (1994: 352) quando afirma que "o relato é um resumo do sonho de todo revolucionário judeu" e de Soares (2002: 222) indicando que "a presença satânica é como a devastadora ocupação das tropas romanas". Do ponto de vista do discurso religioso, poderíamos afirmar que a violência do império romano, através de suas legiões, adquire uma conotação "diabólica".

De acordo com o relato o demônio é um só, mas se chama de "legião", porque são muitos. Trata-se do mesmo termo para se referir à divisão armada de Roma que controlava com mão de ferro a Palestina. Deve-se ressaltar que "conhecer o nome" de alguém, naquela cultura, significava a pretensão de dominar essa pessoa e ser mais forte do que ela. O espírito impuro, portanto, ao responder a Jesus procura demonstrar todo seu poder e, com isso, a partir do simbólico, subjugar o mais fraco. Os demônios expulsos por Jesus entram nos porcos que eram considerados "os animais mais impuros de todos e os que melhor podiam definir os romanos" (Pagola: 208). Chouraqui (1996: 93) é ainda mais incisivo ao afirmar que "o homem está possuído pelo demônio como Israel pelas legiões romanas". E Bortolini segue na mesma direção (2003, p.105) ao expressar que o "possesso é símbolo de um povo politicamente dominado".

O texto é narrado à procura de seu clímax e, por conta disso, os porcos se precipitam ao mar onde a "resistência judaica queria vê-los submersos 
para sempre" (Pagola: 208). Dessa forma, a ruína dos porcos também significaria a libertação da escravidão sob o poder romano. Storniolo (1992: 89) ratifica a informação: "também o porco era considerado animal sagrado e um dos símbolos do poder romano". O porco era precisamente o símbolo da $\mathrm{X}$ legião romana que controlava a partir da Síria a região palestina (Chouraqui: 1996).

Ao escutar o discurso de Jesus os ouvintes não podiam pensar senão na legião romana estabelecida em Damasco e encarregada de manter a ordem naquela região e de fazer respeitar a pax romana. Não devemos nos esquecer que Roma havia enviado à Judéia e à Síria suas melhores tropas para manter a ordem constantemente perturbada pela população revoltosa (Chouraqui, p. 94). No texto do evangelho de Marcos, portanto, a legião romana assume características sobre-humanas e, mais do que isso, assume um perfil que atende forças sobre-humanas e não-humanas da maldade.

\section{A cruz: quando a violência atinge status de selvageria}

A crucificação era e permaneceu uma punição política e militar do Império Romano. De acordo com Crossan (2008: 138-39) a crucificação romana era um instrumento para contra-atacar o que se considerava terrorismo de estado e sua função era impedir a resistência ou a revolta, especialmente entre as classes inferiores. Relacionado a Jesus é possível dizer que o Império Romano raramente exercia seu poder sem necessidade. Nesse sentido, muito possivelmente o império "não crucificava professores ou filósofos"... se Jesus tivesse sido apenas uma questão de palavras ou ideias, os romanos provavelmente o teriam ignorado" (Crossan, 2008: 15). Muito mais do que as palavras, eram as ações de Jesus que incomodavam o projeto da disseminação da pax Romana.

Um dos maiores trunfos dos militares romanos era a crucificação. Ela era utilizada como um instrumento para aterrorizar os povos subjugados e, assim, submetê-los ao regime imperial. Necessariamente a cruz evocava não podemos pensá-la de forma neutra - o terror de tortura e punição para escravos e povos resistentes ao domínio romano. Percebe-se, portanto, que a cruz possui um horizonte social bastante característico, isto é, nela e para ela estão destinados os agitadores.

Horsley e Hanson (1985: 44) acrescentam que os exércitos romanos em seu avanço sobre os territórios judeus trataram os habitantes com 
brutalidade com o objetivo de induzir o povo à submissão. Segundo os autores "repetidamente, os exércitos romanos incendiaram e destruíram completamente cidades e massacraram, crucificaram ou escravizaram suas populações". Um dos exemplos mais notáveis é anotado por Josefo ao registrar que "quando Cássio conquistou Tariquéia, na Galiléia, escravizou cerca de 30 mil homens e posteriormente escravizou o povo de importantes cidades regionais como Gofna, Emaús, Lida e Tamna" (apud Horsley, 1995: 44).

No mundo romano a crucificação, portanto, é plenamente coroada de significação política. Elliot (2004: 169) afirma que como meio de punição capital de crimes hediondos, a crucificação era a "pena romana suprema", mas quase sempre infligida às classes inferiores. Ela era a punição típica para escravos como instrumento de dissuasão (Hengel: 1978).

Crossan (1995: 54), numa referência a Tácito, mostra a descrição do Império Romano a partir da visão do general Calgaco antes de seu encontro fatal com o poderio militar no nordeste da Escócia. Trata-se de um texto exemplar:

Saqueadores do mundo, agora que a terra não é o bastante para as suas mãos devastadoras, eles exploram até o mar: se o inimigo possui riquezas, eles têm ganância; se ele é pobre, são ambiciosos; Oriente nem Ocidente os fartaram; são o único povo da humanidade que contempla com a mesma paixão a escassez - terras pobres - e a fartura terras ricas. Pilhar, matar, roubar, a isso chamam erradamente de império: trazem desolação e chamam isso de paz.

A cruz era considerada a punição mais agravante que se poderia implementar. Em termos de severidade, contribui Hengel (p. 35), a crucificação somente pode ser comparada aos jogos de entretenimentos populares nos quais se lançavam as vítimas às bestas feras. Todavia, a crucificação era muito mais comum porque não necessitava de festa popular para ser executada com todo o seu rigor. Bastava, na verdade, de madeira suficiente para decorar a estradas do império. E, nesse sentido, o espetáculo seguiria um fluxo contínuo, não dependendo, é claro, do calendário dos festivais.

A percepção de Dorothe Solle (p. 169) é essencial a fim de compreendermos a função social da cruz no primeiro século:

O símbolo da religião dos escravos é a cruz, variante da pena capital reservada aos escravos (...). É em primeira linha um assassinato religioso e político (...). É sobretudo um símbolo da realidade (...) A cruz não é nenhuma invenção teológica, mas a resposta mil vezes dada pelo mundo à tentativa de libertação. 
Percebemos nela a ideologia dos poderosos, tomados de zelo pela preservação da ordem estabelecida, vemos a crueldade e o sadismo dos soldados, que colaboram com eles e obedecem às ordens.

A cruz, no primeiro século, se contrapõe à liberdade. Nelas - sempre será necessário pensar nesse instrumento de tortura no plural pois, afinal, as cruzes se espalharam absurdamente pelas estradas da Palestina - não são pendurados apenas corpos. Ali permaneceram histórias de vida que não puderem ser completadas, sacrificadas que foram no altar do império. Nas cruzes do Império se encontram corpos de escravos e nos corpos uma esperança de libertação.

\section{Conclusão}

Roma jamais atuava sozinha nos países subjugados. Junto a ela se encontravam como aliadas as elites das províncias. A aliança estratégica certamente era baseada em razões econômicas, todavia, não puramente. Havia também uma razão ideológica que poderia ser assim expressada: o lugar e o domínio de Roma no cenário mundial eram o desejo dos deuses. Ideias como essa justificavam todos os esforços para submeter os povos ao poder da nova ordem imperial, assim como justificavam a sociedade altamente hierárquica do império. Enquanto as elites das províncias se enriqueciam com a associação ao poder imperial, a população sofria múltiplas formas de violência. Submeter-se a Roma passaria a ser considerado o mesmo que se submeter ao desejo dos deuses e, de forma consequente, participar de suas bênçãos.

Nesse mesmo primeiro século, Jesus aparecerá no cenário de múltiplas violências como mais um dentre tantos palestinos controlados pelo poder da nova ordem imperial. As ações e discursos de Jesus serão produzidas numa situação de injustiça sistêmica e de maldade estrutural em que uma grande porcentagem de pessoas sacrificadas era a responsável em tornar o processo de construção do império possível. Um império que se construía e se constituía sobre o corpo de milhares de vítimas.

\section{Fontes Antigas}

JOSEFO, F. Guerra dos judeus. Livro II. Curitiba: Juruá, 2009a.

JOSEFO, F. Guerra dos judeus. Livro III. Curitiba: Juruá, 2009b.

JOSEFO, F. Guerra dos judeus. Livro V. Curitiba: Juruá, 2009c. 


\section{Referências Bibliográficas}

BORTOLINI, J. O evangelho de Marcos. São Paulo: Paulus, 2003.

CHOURAQUI, A. Marcos. Rio de Janeiro: Imago, 1996.

CROSSAN, J. D. Jesus: uma biografia revolucionária. Rio de Janeiro: Imago, 1995.

CROSSAN, J. D. O essencial de Jesus: frases originais e primeiras imagens. Belo Horizonte: Jardim dos Livros, 2008.

CROSSAN, J.D. O Jesus histórico. Rio de Janeiro: Imago, 1994

CROSSAN, J.D. O Nascimento do Cristianismo. O que aconteceu nos anos que se seguiram à execução de Jesus. São Paulo: Paulinas, 2004.

ELLIOT, N. A mensagem antiimperial da cruz. In: HORSLEY, R. A. (Org.). Paulo e o Império: religião e poder na sociedade imperial romana. São Paulo: Paulus, 2004. p. 169-184.

FRANCO, H. Jr. Cocanha - a história de um país imaginário. São Paulo: Companhia das Letras, 1998.

HENGEL, M. Crucifixion: in the ancient world and the folly of the message of the cross. Fortress Press: Philadelphia, 1978.

HORSLEY, R. A. Jesus and the Spiral of Violence. San Francisco: Harper \& Row, 1987.

HORSLEY, R. A. (Org.). Paulo e o império: religião e poder na sociedade imperial. São Paulo: Paulus, 2004.

HORSLEY, R. A.; HANSON, J. S. Bandidos, profetas e messias. São Paulo: Paulus, 1995.

KOESTER, H. Introdução ao Novo Testamento. São Paulo: Paulus, 2005. v. 1.

PAGOLA, José A. Jesus - aproximação histórica. Petrópolis: Vozes, 2010.

SOARES, S.G. et al. Evangelho de Marcos. Vol. I:1-18. Petrópolis: Vozes, 2002

SOUTHERN, P. The Roman Army. Oxford: Oxford University Press, 2007

STORNIOLO, I. Como ler o evangelho de Lucas. São Paulo: Paulus, 1992. 
WEBSTER, G. The Roman Imperial Army. New Jersey: Barnes \& Noble Books, 1985.

WENGST, C. Pax Romana: pretensão e realidade. São Paulo: Paulinas, 1991. 